\title{
DIE KARAKTERISTIEK VAN DIE ARMINIANISME
}

\section{DRS. J. H. KOEKEMOER}

\section{Inleiding:}

(i) Die Arminiane of Remonstrante is die volgelinge van Jacobus Arminius, wat sy leerstellings onderskryf, aanvaar en uitgebou het.

In hulle eie woorde is hulle ,'n geloofsgemeenskap wat gewortel in die evangelie van Jesus Christus en getrou aan Sy beginsel van vryheid en verdraagsaamheid, God wil vereer en Hom wil dien."1)

(ii) Hulle het voorgekom uit die stroming van die Nederlandse Protestantisme van die $16 \mathrm{e} \in \mathrm{eu}$, wat ,nasionaal gereformeerd" genoem kan word. ${ }^{2}$ )

Die nasionaal gereformeerdes was 'n groep Reformatories gesindes in Nederland wat naas die Lutherane en Anabaptiste 'i eie groep vorm wat of teenoor die Calviniste te staan kom of hulle min of meer by hulle aangesluit het. In die begin is hulle soms ook sakramentariërs genoem vanweë die afkeer wat hulle ten opsigte van die altaarsakrament aan die dag gelê het. Dit was egter nie 'n wesenskenmerk van die groep nie. Hulle was een in hulle verwerping van uitwendige vorms en seremonies, een in hulle soeke na die eenvoud van die evangelie, een in die klem wat hulle gelê het op die persoonlike geloofsvertroue. Daar was 'n noue verband met die Bybelse Humanisme van Erasmus.

(iii) Uit die samevloeiing tussen die Reformasie en die Bybelse Humanisme van Erasmus het nou 'n soort van „Bybelspraktiese Christendom" ontstaan wat baie klem gelê het op die mens en sy waardigheid.

(iv) Erasmus het van sy standpunt gepraat, as 'n Christelike filosofie - 'n term wat hy aan Chrysostomus ontleen - en waarmee hy bedoel het 'n moralisties gekleurde Christendom waarin Christus hoofsaaklik die hemelse leraar is en waarin die klem sterk val op die Christen se verantwoordelikheid, vryheid en werksaamheid. bou.

(v) Dit is op hierdie ,teologie" wat Arminius hoofsaaklik

(vi) Dit is nodig om kortliks aan Arminius aandag te skenk omdat daar 'n wesenlike ooreenstemming is tussen sy verklaring en die van die Arminiane.

1) Encyclopedie van het Christendom, Protestants Deel, Amsterdam, Elsevier Brussel MCMLV, Bls. 641 .

2) Encyclopedie van het Christendom. 


\section{Jacobus Arminius (1560-1609)}

Hy is gebore op 10 Oktober 1560 te Oudewater as seun van 'n messemaker Herman Jacobsz. Nadat sy ouers hom op jeugdige leeftyd ontval het, is hy opgevoed deur die priester Theodorus Aemelius.

In 1576 word hy student aan die pasgestigte Universiteit te Leiden waar hy spoedig hoë aansien onder die hooglerare en studente verwerf. In 1582 gaan hy na Geneve waar hy onder die opvolger van Calvyn naamlik Beza studeer. Sy studie in Switserland bring hom ook in aanraking met Uytenbogaert wat later die leier van die Remonstrante sou word.

$\mathrm{Na}$ sy terugkeer word hy in 1588 predikant te Amsterdam waar dit spoedig geblyk het dat hy afwykende leerstellinge verkondig toe hy deur Plancius bestry is oor sy preke na aanleiding van Rom. 7.

Dit het egter nog nie tot 'n uitbarsting gelei nie en in 1603 word hy benoem as hoogleraar aan die Universiteit te Leiden. En alhoewel sy benoeming deur Franciscus Gomarus teengestaan word vanweë sy onregsinnigheid, baat dit niks nie. Hier het dit dan ook spoedig geblyk dat hy wel afwykende idees het toe hy deur Gomarus teengestaan word oor sy opvattings oor die predestinasie. Die stryd het eers in 'n teologiese debat aan die akademie ontbrand maar dit het later ook na die kerke uitgebrei toe die leerlinge van Arminius sy afwykende gevoelens van die kansels af verkondig het. Voordat die konflik egter tot 'n spits gedryf kon word is Arminius in 1609 aan tering oorlede.

\section{Verdere Historiese Verloop:}

Die aanhangers van Arminius het tot partyvorming in die kerk oorgegaan, onder leiding van Uytenbogaert, op 'n geheime samekoms te Gouda. Op 14 Januarie 1610 het hulle besluit om hulle tot die state van Holland te rig met 'n Remonstransie waarin hulle in 5 artikels 'n uitvoerige uiteensetting gee van hulle gevoelens insake verkiesing en verwerping, die genoegdoening van Christus, die verdorwenheid en bekering van die mens en die verloorbaarheid van die geloof. Verder stel hulle dat oor kerklike sake die oppergesag aan die owerheid toekom en dat daar vryheid moet bestaan om die Konfessie en Kategismus op sekere punte te hersien.

Hierdie punte het toe in die middelpunt van die stryd gestaan wat uiteindelik op die sinode van Dordrecht uitgeloop het waar die leer van die Remonstrante in die geheel verwerp is. 
$\mathrm{Na}$ die sinode se uitspraak is daar toe op 30 September 1619 die Remonstrantse Broederskap gestig waarvan Uytenbogaert tot sy dood in 1644 die erkende leier gebly het.

Daar is ook besluit om 10 verbanne predikante en 4 studente na die Vaderland te stuur om die gemeentes te help om 'n Konfessie of "verklaring van geloof" sonder formulierdwang op te stel en ouers te waarsku om nie hulle kinders deur gereformeerde onderwysers te laat onderrig nie.

Die konfessie het in 1621 verskyn met 'n inleiding geskryf deur Episcopius. Die konfessie is nie deur almal aanvaar nie omdat hulle naas die Bybel geen konfessie begeer het nie.

In 1634 het Episcopius die hoogleraarsamp aan die Remonstrantse seminárie te Amsterdam aanvaar waar aanvanklik 7 studente was. Dit is in 1873 na Leiden verplaas en het as hooglerare gekry C. P. Tiele, H. Y. Groenewegen, G. J. Heering en G. J. Sirks.

In 1950 is daar ook 'n nuwe Kerkorde aanvaar. Die hoogste bestuur van die Remonstrantse Broederskap is 'n Algemene Vergadering.

\section{Die Leer van Arminius:}

(i) Soos reeds gesê, kan die leer van Arminius teruggevoer word na die Bybelse Humanisme van Erasmus. Hy het baie klem gelê op die menslike waardigheid, die persoonlike verantwoordelikheid en die vryheid van die mens.

(ii) Daarenteen het hy weinig waarde geheg aan die dogmata en sakramente van die Kerk. Sy teologie is veral gebou op die bergrede, dit verwerp die verdorwenheid van die mens en lê baie klem op die verdraagsaamheid en vrede sowel binne as buite die kerk.

(iii) Die mens is nie geheel onwaardig voor God nie, maar hy beskik oor sedelike kragte waardeur hyself ook iets aan sy saligheid kan en moet doen. 'n Versigtige semi-Pelagianisme dus, waar die menslike medewerking met Gods genade om die heil te vind noodsaaklik is.

(iv) Ten opsigte van die uitleg van die Heilige Skrif, was Arminius 'n voorstander van 'n vry kritiese metode van uitleg waar hy alleen aan die Heilige Skrif gebonde is om dit volgens sy gewete te interpreteer sonder gebonde te wees aan teologiese opvattinge en dogmas wat volgens hom van buite af opgelê was.

(v) Oor die predestinasie het Arminius gestel dat dit 'n „decretum van die welbehae van God in Christus is waardeur God self van ewigheid af besluit het om die gelowiges, wat God besluit het om met die geloof te begiftig, te regverdig en aan 
te neem tot Sy kinders. Dit gaan dus vir hom daarom dat die uitverkiesing tot saligheid plaasvind op grond van die deur God vooruit gesiene geloof. Die verwerping van 'in sekere aantal mense is 'n besluit van die strenge wil van God waardeur God van ewigheid af besluit het dat die ongelowige as gevolg van sy eie skuld en op grond van die regverdige oordeel van God nie kan glo nie omdat hy buite die gemeenskap met Christus gestel is en daarom tot die dood verwys is."

(vi) 'n Verdere verskil tussen Arminius en Gomarus was dat Arminius 'n infralapsariër was terwyl Gomarus supralapsaries was. Die infralapsarisme is die siening waarin die volgorde van die Godsbesluit, die uitverkiesing en verwerping na die val van Adam plaasvind. Die sonde word gesien as iets wat God wel toelaat maar wat Hy nie eintlik wil nie.

By die ,supralapsarisme het die Godsbesluit van verkiesing voor die besluit van die sondeval in die volgorde van besluite gekom."

(vii) „Arminius wou vanuit die Christologie 'n korreksie aanbring op die uitverkiesingsleer van Calvyn."3) Die diskussie tussen hom en Gomarus het dan ook op die vlak van die Godsleer en die daarmee verbonde leer omtrent Christus beweeg, waarby een van die hoofpunte dan was dat Arminius betoog het dat die volstrekte deurvoering van die predestinasie in die sin van die supralapsarisme God die outeur van die sonde sou maak.

\section{Die Arminiaanse Leer:}

(i) Hulle leer is uiteengesit in die Remonstransie waarin hulle hulle tot die state van Holland gerig het.

(ii) Die vyf punte kan kortliks as volg saamgevat word:

1. God het diegene wat glo tot die saligheid verkies.

2. Christus het vir alle mense gesterf.

3. Die saligmakende geloof het sy oorsprong in God.

4. Die genade is egter wederstandelik.

5. Die moontlikheid van die afval van die gelowiges.

(iii) Alhoewel dit op die oog af lyk of van hierdie stellings kerngesond is, is hulle tog nie so geheel onskuldig nie. In punte een en twee lê die angel byvoorbeeld in die "geloof", wat hulle sien as 'n menslike beslissing, wat dan die grond sou vorm van Gods uitverkiesing. Hulle meen dat daar gekies moet word tussen Gods uitverkiesing en die mens se verantwoordelikheid. Daarom verwerp hulle die eerste, alhoewel hulle nog in 'n sekere sin aan die uitdrukking vashou.

3) G. J. Hoenderdaal, Verklaring van Jacobus Arminius, De TydstroomLochem 1960, bls. 31 . 
(iv) In punte (3) (Die saligmakende geloof het sy oorsprong in God) en (4) (maar hierdie genade is wederstandelik) gaan dit daarom dat God aan almal die geloof aanbied en weet wie dit sal aanvaar. Die gevalle mens het in 'n sekere sin 'n vrye wil. Dit is daarom sy eie skuld as hy die heil wat God hom aanbied verwerp. As hy die heil egter aanvaar, het dit nog ook in 'n sekere sin 'n verdienste. Daartoe moet die genade wel voorafgaan en dit begelei, maar die vrye wil doen ook iets. Die geloof is ' $n$ voorwaarde vir die saligheid, 'n verdienstelike prestasie van die mens, wat deur die groter prestasie van die offer van Jesus Christus aangevul word. Die arminiane dink dus redelik optimisties oor die mens. Die mens is ondanks sy val nie geheel onwaardig voor God nie, maar hy beskik oor sedelike kragte waardeur hyself ook iets aan sy saligheid kan en moet doen.

(v) In die vyfde artikel gaan dit oor die moontlikheid van die afval van die heiliges, omdat hulle ter enige tyd die besluit um te glo ut hersiening ká!i eem. Hierdie leerstelling van di.? Remonstrante moet noodwendig by die gelowige '" groot mate van twyfel laat ontstaan. Daarom wys die Dortse leerreëls in Hoofstuk 5, verwerping van die dwalinge 5, hulle dan ook af wat leer „dat 'n mens geen sekerheid van die toekomstige volharding in hierdie lewe kan hê nie sonder 'n besondere openbaring." Want deur hierdic leer word die vaste troos van die ware gelowiges in hierdie lew? wegseneem en die twyfelinge van die Psus-gesindes in die Kerk weer ingevoer; terwyl die Heilige Skrif hierdie sekerheid telkens aflei nie lit 'n besondere en buitengewone openbaring nie, maar uit die werktekens en aan die kinders van God en uit die altyd standhoudende beloftes van God."

Die Remonstrante het dit immers ook gestel „dat het prijselijc ende profijtisch is zijne volherdigwaerdigheijt te twyffele.") En volgens Episcopius is die grootste gevaar vir die saligheid „de securiteit." Want „de securiteit is het aangenaamste voor het vlees. Die vleselijke mensen begeren haar en hebben haar lief. Bijna alle anderen hellen min of meer tot haar over. $\mathrm{Er}$ is weinig toe nodig of zij vervallen er in." ${ }^{\text {) }}$

Dr. G. J. Heering wat met instemming hierdie woorde weer gee in 'n gedenkboek by die 300 -jarige bestaan van die Remonstrantse broederskap voeg daaraan nog toe: „De gelowige mag de twijfel omtrent zijn uitverkiesing niet te spoedig verlieztn."

4) C. van der Waal, Liguidatie der Reformatie, J. Boersma bls. 18.

5) C. van der Waal, a.w., bls. 18.

6) C. van der Waal, a.w., bls. 18. 
(vi) Verder stel die Remonstrante dat hulle gehecl die staatsgesag oor die Kerk erken en verwelkom.

(vii) Ook was hulle gekant teen elke handhawing van 'n geloofsbelydenis wat as belydenisdwang gesien word.

(viii) Hierdie hele stryd raak die 16 de Aritkel van die Nederlandse Geloofsbelydenis op 4 punte:

Die Remonstrante wil niks weet van wat in die N.G.B. genoem word:

(1) „sy ewige en onveranderlike raad nie."

(2) Verder het hulle beswaar teen die woorde ,diegene wat hy uitverkies het."

(3) Die gedeelte "sonder om enigsins hulle werke in aanmerking te neem" kan hulle nie aanvaiar nie.

(4) Ten slotte staan die bewering ,deurdat hy die ander laat in hulle val en verderf"') in lynregte teenspraak met die Algemene Heilswil van Gad, sê hulle.

(ix) Die Remonstrante het verder ook beswaar gehad teen die woorde van die Heidelbergse Kategismus: dat ek daarvan (d.i. van die Kerk) 'n lewende lidmaat is en ewig sal bly (vraag en antwoord 54). In sulke uitsprake, sê hulle, word die vryheid van die wil bedreig.

\section{Beoordeling:}

(i) In die beoordeling van die Arminianisme sal ons daarmee rekening moet hou dat ons ook by hulle 'n sekere beskeidenheid oor die leer van die kerke raakloop. Die soort van beskeidenheid is egter tipies van alle dwaalleringe en is in sy wese eintlik niks anders as vreesagtigheid nie. Saam met Calvyn kan ons sê dat agter die beskeidenheid dikwels die hoogmoedige gedagte skuil om God aan die mens se oordeel te onderwerp.

(ii) Uit vrees dat God deur die gangbare verkiesingsteologie tot outeur van die sonde gemaak sou word het die Remonstrante tot 'n heel ander siening oor die saak gekom. Hulle leer wel in die Remonstransie dat die mens die saligmakende geloof nie uit homself het nie $^{3}$ ) maar hierdie belydenis word verswak, as dit nie geheel en al weerspreek word deur hulle twyfel aangaande die volharding van die heiliges nie ${ }^{5}$ ) en hulle ontkenning van die onwederstandelikheid van die Heilige Gees ${ }^{t}$ ).

(iii) Van die twee groot motiewe van die verkiesing naamlik dat ons geheel op genade aangewys is en geheel in Gods trou

i) A. D. R. Polman, Onze Nederlandsche Gelefoosbelydenis T. Wever Franelier, Tweede deel, bls. 202.

8) Kerkboek van die Nederduitsch Hervornde Kerk van Afrika. Usie belydenisskrifte, gebede en formuliere, bls. 101. 
mag rus het die laaste verval en is die eerste kragteloos gemaak.

(iv) In die posisie van die Remonstrante is daar egter ook 'n tragiese element aanwesig. Hulle was naamlik so bevrees vir die gedagte dat God "die outeur van die sonde sou word," dat hulle uit reaksie daartoe gekom het om God selfs nie meer as die enige outeur van die genade te erken nie. By hulle voorstelling kom die beslissing oor die heil en verwerping in die hande van die mens te lande.

(v) Dit word gou duidelik dat ons hier met 'n liberalisme te doen het wie se geloof in die mens, sy moontlikhede en bekwaamhede, diep setel. Hier word daarom wel deeglik afbreuk gedoen aan die eer van die enige soewereine God van die Bybel in wie alleen geglo moet word.

(vi) Die Bybelse leer oor die verdorwenheid van die mens en sy totale onmag tot die goeie word hier heeltemal misken.

(vii) Tereg kan daarom miskien opgemerk word dat die Arminianisme die medium was waardeur die Humanistiese gees van die Renaissance in die taal van die Kerk vertaal is. Want dit is hierdie gees wat nie wil erken dat die mens in sy diepste wese sondaar is nie maar wat die menswaardigheid, die regte en vryheid van elke mens wil eerbiedig as onaantasbaarhede wat tot sy wese behoort. Vanaf hierdie gees van die Humanisme is dit maar een stap na die Social Gospel.

(viii) Die feit dat die Remonstrante teen die handhawing van die belydenisskrifte was kan 'n mens maklik sien in die lig van 'n ander bekende spreuk: Die Skrif bring verdeeldheid, die gewete bring eenheid.

Die Remonstrante wou met 'n minimum belydenis volstaan, 'n soepele basis-formule, terwyl hulle niks wou weet van die onderskeiding tussen die ware en valse Kerk en die suiwere prediking, die regte sakramentsbediening en die Christelike tug as kenmerke van die ware kerk nie.

(ix) Daar dien ook op gewys te word dat as die Dortse leerreëls die leer van hulle verwerp wat leer „dat die volharding van die heliges nie ' $n$ vrug van die verkiesing of 'n gawe van God is nie, wat deur die dood van Christus verwerf is nie, maar 'n voorwaarde van die Nuwe Verbond wat die mens - soos hulle sê - voor sy beslissende verkiesing en regverdigmaking deur sy vrye wil moet volbing" dit nie gaan oor die afwysing van 'n leer wat net maar die geloof oorskat nie maar 'n prinsipiële misvatting oor die geloof het.

(x) In hulle beginselverklaring sê die Remonstrante dat hulle ,'n geloofsgemeenskap is wat gewortel in die evangelie van 
Jesus Christus en getrou aan Sy beginsel van vryheid en verdraagsaamheid God wil vereer en dien." $)$

- Alhoewel dit 'n onskuldige en op die oog af kerngesonde stelling lyk is dit tog nie so nie. Want die vryheid waarna hier verwys word is niks anders as 'n verwysing na die belangrikheid van die mens en sy bekwaamhede nie.

En nou is dit tog opvallend dat hierdie begrip vryheid ook 'n baie belangrike rol speel in die huidige teologiese ontwikkeling, die sogenaamde Nuwe Teologie. En by albei gevalle gaan dit in die vryheid hier om die mens wat aan homself 'n subjeksposisie toe-eien. Hierteenoor sal ons beslis afwysend moet staan omdat vryheid dan ' $n$ doel in sigself word. En dit kan tog nooit nie. Ons sal saam met Augustinus moet sê „Deo servire libertas", "om God te dien is die vryheid."

(xi) Wat die oorsprong en voorsetting betref is die Arminiaanse teologie die grond van hierdie nuwe teologiese ontwikkeling.

Want in die Nuwe Teologie gaan dit om 'n mens wat mondig geword het (Bonhoefer). Met hierdie mondige, moderne mens, sy lewens- en wêreldbeskouing word groot erns gemaak. Sy sienswyse, sy behoeftes moet eers vasgestel word en dan moet die evangelie aan hom verkondig word soos dit vir hom aanvaarbaar is. Bultman het reeds gestel:

„Dit het onmoontlik geword om elektriese lig en radio te gebruik, om moderne medisyne en mediese ontdekkinge tot ons beskikking te hê en terselfdertyd in die Nuwe Testamentiese wêreld van demone en geeste te glo." ${ }^{10}$ )

(xii) Ook Robinson (J. A. T.) lê baie klem op die mens. Dat God van buite af gebooie neerlê waaraan die mens hom moet hou is 'n supra-naturalistiese moraal wat verkeerd is. Vir die moderne mens is dit heeltemal onaanvaarbaar. Ons moet by die mens begin want slegs as mens $\mathrm{en}$ in die mens kan sy tydgenote die Seun van God sien. Die mens het uiteindelik net een gebod: om lief te hê. En dit is 'n appél op die mens se vermoë sonder dat hy eers gehoor het. Die mens is vry en het 'n edele inbors en hart.

(xiii) So lyk dit dan of dit maar altyd weer dieselfde ou dwaling is. Hoogmoed, wat God aan die mens wil onderwerp.

9) Fncyclopedie van het Christendom. Protestants Deel, Amsterdam Elsevier Brussel, p. 641 . 